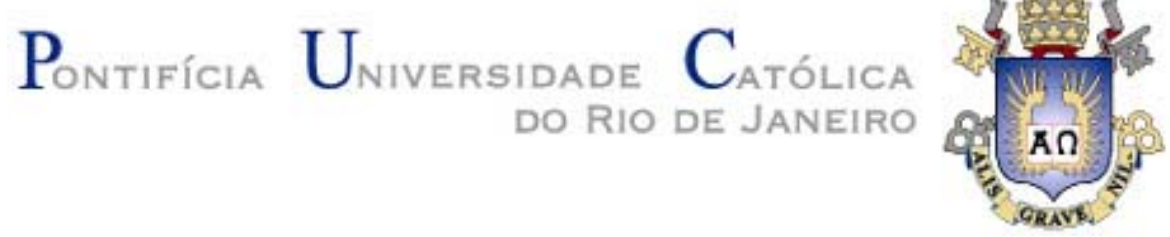

Fernando Ormonde Teixeira

Otimização Financeira de Parque Eólico no mercado de energia do Brasil

Dissertação de Mestrado

Dissertação apresentada ao Programa de Pósgraduação em Administração de Empresas da PUCRio como requisito parcial para obtenção do título de Mestre em Administração de Empresas

Orientador: Prof. Leonardo Lima Gomes 


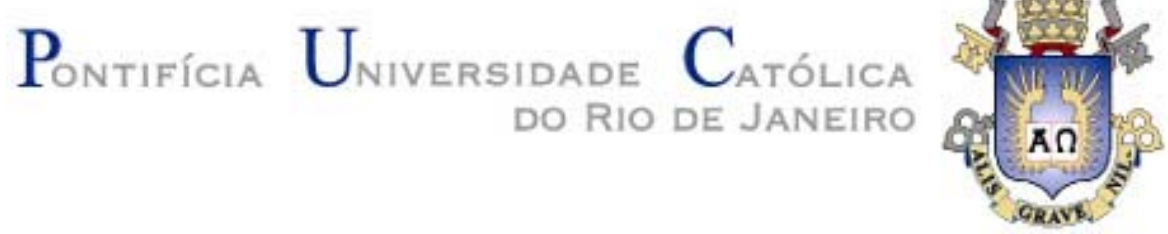

Fernando Ormonde Teixeira

\section{Otimização Financeira de Parque Eólico no mercado de energia do Brasil}

Dissertação apresentada como requisito parcial para obtenção do grau de Mestre pelo Programa de PósGraduação em Administração de Empresas da PUC-Rio. Aprovada pela Comissão Examinadora abaixo assinada.

Prof. Leonardo Lima Gomes

Orientador

Departamento de Administração - PUC-Rio

Prof. Marcelo Cabus Klotzle

Departamento de Administração - PUC-Rio

Prof. Mario Domingues de Paula Simões

Profa . Mônica Herz

Vice-Decana de Pós-Graduação do CCS - PUC-Rio

Rio de Janeiro, 10 de abril de 2015 
Todos os direitos reservados. É proibida a reprodução total ou parcial do trabalho sem autorização da universidade, do autor e do orientador.

\section{Fernando Ormonde Teixeira}

Graduado em Economia pela PUC-Rio (2012), mestre em Administração de Empresas pela PUC-Rio com ênfase em Finanças da Energia (2015). É Pesquisador pelo Núcleo de Pesquisa em Energia e Infraestrutura (NUPEI) da PUC-Rio atuando em Pesquisa e Desenvolvimento (P\&D) na área de Finanças da Energia. Também efetua pesquisas pelo Instituto Brasileiro de Economia (IBRE).

Ficha Catalográfica

Teixeira, Fernando Ormonde
Otimização financeira de parque eólico no
mercado de energia do Brasil / Fernando Ormonde
Teixeira ; orientador: Leonardo Lima Gomes. - 2015.
$62 \mathrm{f}$ : : il. (color.); $30 \mathrm{~cm}$
Dissertação (mestrado)-Pontifícia Universidade
Católica do Rio de Janeiro, Departamento de
Administração, 2015.
Inclui bibliografia
1. Administração - Teses. 2. Vento. 3. Parque
eólico. 4. Finanças. 5. Energia. 6. VaR. 7. CVaR. 8.
Brasil. 9. Ceará I. Gomes, Leonardo Lima. II. Pontifícia
Universidade Católica do Rio de Janeiro.
Departamento de Administração. III. Título.

CDD: 658 


\section{Agradecimentos}

Há momentos na vida em que escrevemos longos textos para agradecer a todos aqueles que, em certo ponto, fizeram diferença em nossas vidas. Evidenciamos, através de uma amostra não aleatória de acontecimentos explicitada, o porquê de estas pessoas merecerem menção.

Este não é um destes momentos. Não por não ter a quem agradecer, longe disso. Não construímos nada sozinhos. Eu apenas não consigo organizar em minha mente as muitas situações vivenciadas de forma a escolher as que merecem registro.

Listo abaixo aqueles que gostaria de agradecer:

- Minha família - Vania, José Carlos e Ana Paula.

- Meu Orientador - Leonardo Lima.

- Membros do NUPEI.

- Aos amigos - Tomás Urani, Gabriel Vasconcelos, Patrícia Caldas, Jefferson Brito, Daniel Camargo, Michelle Bandarra, Gláucia Fernandes, Luciana Pereira e Ralph Stier.

Por fim, um agradecimento especial à Queiroz Galvão Energias Renováveis e ao projeto de P\&D da ANEEL que disponibilizaram todo o suporte necessário para que este trabalho se concretizasse. 


\section{Resumo}

Teixeira, Fernando Ormonde; Gomes, Leonardo Lima. Otimização Financeira de Parque Eólico no mercado de energia do Brasil. Rio de Janeiro, 2015. 62p. Dissertação de Mestrado - Departamento de Administração, Pontifícia Universidade Católica do Rio de Janeiro.

Investigam-se modelos econométricos que sejam capazes de efetuar uma previsão mensal de vento em um parque eólico no Ceará. São testados modelos da família ARMA que consigam capturar a sazonalidade inerente ao movimento das massas de ar e que tragam benefícios aos empreendimentos eólicos localizados no Brasil e na região. Para tal, a previsão de vento é transformada em previsão de geração de energia. Em seguida, é elaborada uma metodologia para encontrar a melhor estratégia de ação a qual maximize o resultado da empresa tendo-se como meta o lucro e restrições de Value at Risk (VaR) e Conditional Value at Risk (CVaR). Os possíveis resultados de geração de energia são simulados concomitantemente com a simulação de preços de liquidação (PLD).

\section{Palavras-chave}

Vento; Parque Eólico; Finanças; Energia; VaR; CVaR; Brasil; Ceará. 


\section{Abstract}

Teixeira, Fernando Ormonde; Gomes, Leonardo Lima. (Advisor). Financial Optimization of a Wind Farm in the brazilian energy market. Rio de Janeiro, 2015. 62p. MSc. Dissertation - Departamento de Administração, Pontifícia Universidade Católica do Rio de Janeiro.

We investigate econometric models that are capable of predicting the wind speed in a wind farm located in the state of Ceará, Brazil. ARMA models are tested to try to capture the seasonality inherent to the wind and that bring benefits to the firms operating wind farms in the region. Wind is converted in power generation to allow predictions to be more precise. Then, a methodology is created to find the best strategy, the one that maximizes the firm's profit. An optimization is made with VaR and CVaR as constraints. The simulated results of power generation are then put together with a simulation of liquidation's price (PLD).

\section{Keywords}

Wind; Wind Farm; Finance; Energy; VaR; CVaR; Brazil; Ceará. 


\section{Sumário}

1. Introdução 11

2. Referencial Teórico 18

2.1. Energia Eólica 18

2.2. Tipos de Modelos de Previsão 21

2.2.1. Modelos de Previsão Físicos (Determinísticos) 22

2.2.2. Modelos de Previsão Estatísticos (Estocásticos) 23

2.2.3. Modelos de Redes Neurais e Modelos Híbridos 25

2.3. Otimização 26

2.3.1. Problemas de Otimização 26

2.3.2. Programação Linear (LP) 28

2.3.3. Value at Risk - VaR 30

2.3.4. Conditional Value at Risk - CvaR 31

3. Metodologia $\quad 34$

3.1. Seleção da Série 34

3.2. Seleção de Modelo de Previsão 35

3.3. Otimização 36

3.4. Passos Metodológicos 38

4. Resultados 41

4.1. Estatísticas Descritivas 41

4.2. Análise de Resultado 44

5. Conclusão 54

6. Referência Bibliográfica 56

Apêndice $\quad 59$ 


\section{Lista de figuras}

Figura 1 - Complementaridade entre regime de ventos e capacidade hidríca de geração

Figura 2 - Sistema elétrico

Figura 3 - Solução de problema de otimização

Figura 4 - VaR e CVaR

38

Figura 5 - Implementação do modelo de otimização 


\section{Lista de tabelas}

Tabela 1 - Comparativo entre ambiente livre e regulado 16

Tabela 2 - Teste de Pearson de correlação 43

Tabela 3 - Teste ADF de raiz unitária $\quad 44$

Tabela 4 - Critérios para escolha de modelo 44

Tabela 5 - Teste de resíduos $\quad 45$

Tabela 6 - Teste de resíduos $\quad 45$

Tabela 7 - Coeficientes do modelo $\quad 60$ 


\section{Lista de gráficos}

Gráfico 1 - Série MERRA concatenada com medições anemométricas

Gráfico 2 - Comparativo entre série MERRA e a medida pelo anemômetro

Gráfico 3 - Teste de capacidade preditiva dos modelos 44

Gráfico 4 - Função de autocorrelação 45

Gráfico 5 - Previsão de geração de energia 46

Gráfico 6 - Comparativo entre geração prevista e realizada 46

Gráfico 7 - Histograma de simulação de potência gerada para um período à frente por um aerogerador

Gráfico 8 - Simulação de potência gerada por um aerogerador 48

Gráfico 9 - Comparativo de lucro entre modelo 'ingênuo' e

resultado da otimização

Gráfico 10 - Comparativo entre quantidade gerada e atuação no mercado a termo

Gráfico 11 - Análise de sensibilidade do lucro - a 51

Gráfico 12 - Quantidade comprada líquida - sensibilidade em a 51

Gráfico 17 - Histograma de previsão de vento um período à frente 61

Gráfico 18 - Simulação velocidade de vento 62

Gráfico 19 - Comparativo entre realizado e previsto - vento 62 